\title{
Socialization Messages in Primary Schools: An Organizational Analysis
}

\author{
Steven Brint, Mary F. Contreras, \\ and Michael T. Matthews \\ University of California, Riverside
}

Using the tools of organizational analysis, this article presents a framework for understanding the volume and content of socialization messages expressed in 64 primary school classrooms. This framework specifies five levels of classroom and school organization in which socialization messages are embedded. It links the behavioral ideals expressed at two of these levels-teacher-initiated interactions in the classroom and schoolwide programs-to the schools' organizational interests in maintaining order and work effort and encouraging students to identify with the school. It links the values expressed at two other levels-the formal curriculum and the routine practices of everyday classroom life-to a blending of old and new cultural influences. The framework specifies two ways in which new values can enter the schools-through the influence of social movements institutionalized with governmental support or the adoption of pedagogical philosophies consistent with changes in adult middle-class life experiences.

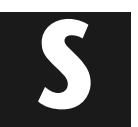

ome of the best-known work in the sociology of education has focused on the contribution of schooling to the formation of children's behavior and values (see, e.g., Dreeben 1968; Durkheim 1923/1961; Jackson 1968; Waller 1932). It is not surprising that some of the best-known work in the field has focused on this topic; socialization has long been considered one of the major societal purposes of schooling (see, e.g., Bendix 1968; Bowles and Gintis 1976; Brint 1998; Collins 1977; Karabel and Halsey 1977; Parsons 1959). In recent years, however, sociologists have shown only a limited interest in the schools' role in socialization; instead, studies of the schools' role in reproducing social inequalities and improving academic achievement have been central.
Given this low level of social scientific interest in school socialization processes, it is perhaps surprising that few topics have been of consistently greater interest to the public than the role of schools in helping to form students' behavior and values. Opinion polls have consistently shown that the public is as concerned about the schools' role in solving social problems, such as drug use and teenage pregnancy, as in dealing with any other educational issue (Gilbert 1988) and that an overwhelming majority think that schools should teach "basic moral values" as one means of combating social problems ( $\mathrm{S}$. Glazer 1996). Nor do teachers consider socialization to be a matter of secondary importance (Farkas, Johnson, and Foleno 2000). 
Social commentators and politicians have also had much to say about the schools' role in socialization. Cultural conservatives, such as former Secretary of Education William Bennett, have urged a return to curricula emphasizing "moral virtues," such as honesty, fairness, perseverance, compassion, and courage. In the introduction to his best-selling The Book of Virtues, Bennett (1993:11) wrote: "Where do we go to find the material that will help our children in [the] task [of developing moral literacy]? The simple answer is we ... have a wealth of material to draw on-materials that virtually all schools and homes and churches once taught to students for the sake of shaping character. That many no longer do is something this book hopes to change."

In the 1990s many cultural conservatives declared that a "culture war" was flaring in the schools between those who advocated multicultural curricula and the importance of modern values of self-expression and those who hoped to maintain an emphasis on Western history and literature and to reintroduce character training in the classroom (see, e.g., Bernstein 1994; Cheney 1987, 1990; N. Glazer 1997; Healey 1996; Hunter 1991, 1994). The concerns of conservative critics helped to spark interest in "character education" curricula, which were adopted by hundreds of school districts during the 1990s (Healy 1996).

But do we really know that socialization messages in the public schools no longer focus on virtues like honesty, fairness, reliability, and responsibility or that they now emphasize the values of cultural diversity, selfesteem, and self-expression? Journalists and politicians may be unreliable guides to answering questions like these because they can be tempted in the nature of their work to rely on anecdotal materials, selectively chosen and presented for dramatic effect. The few recent studies by social scientists have looked at only a limited set of indicators of the schools' role in socialization. Some have concentrated on representations of American heroes in textbooks or on teachers' answers to questions about values they consider important to teach (see, e.g., Farkas and Johnson 1996; Fitzgerald 1979; Frisch 1989;
Sharp and Wood 1992; Wong 1991), ${ }^{1}$ whereas others have discussed the subtle ways in which teachers can act as moral exemplars in the classroom (Jackson, Boostrum, and Hansen 1993). However, no studies have investigated the range of socialization messages that are prevalent in today's schools or the relationship of contemporary socialization messages to the structure of schooling or the larger social contexts in which schools are embedded. In so far as social theorists have discussed school socialization messages in these more comprehensive terms, their work has often appeared as a Foucauldian critique of the "disciplinary regime" of the school and an appreciation of the subcultures of students' resistance to this "regime" (see, e.g., Giddens 1984; McLaren 1989; Willis 1979). ${ }^{2}$ In the absence of research, it is not clear that school socialization messages fit these images of authoritarian control any better than they fit the images of moral abandonment or cultural conflict favored by conservative critics.

The analysis presented in this article is based on a view of schools as multichannel and multilevel organizations set in a specific sociohistorical context. Although we present both qualitative and quantitative data, the article is intended to be read primarily as providing a conceptual framework for understanding the volume and content of the activities of today's schools in the area of socialization. This framework is based on an examination of socialization messages found at five levels of classroom and school organization. The framework includes an analysis of the major organizational and societal forces shaping the socialization messages of today's schools at each level, including an analysis of why the content of messages varies across levels.

Because we are interested in the socialization messages of schools, our analysis focuses on the actions and practices of teachers and principals. It does not address a number of important issues related to school socialization, including the distribution of conformist and nonconformist students, students' interactions with one another and with school authorities, and the complexities in their relationship to the socialization messages of the school. We believe that a clear understanding of these issues depends, in many ways, on 
first understanding the socialization climate of today's schools as expressed in the actions and practices of teachers and principals.

Our research began with a simple question: Have cultural conservatives accurately perceived a shift in school socialization from an emphasis on moral virtues to a celebration of cultural diversity, self-esteem, and selfexpression? Although our analysis provides an answer to this question, our interest gradually broadened toward thinking about how to understand the overall volume and content of socialization messages in the schools. As our interest broadened, so did the scope of our inquiry. We began by concentrating exclusively on messages that are conveyed through teacher-initiated interaction in the classroom. We gradually concluded, however, that such a treatment would leave out a large proportion of the total number of socialization messages conveyed by the school. Teachers do communicate values in their face-to-face interaction with students, but values are also communicated in other ways. In the schools we visited, teachers and principals sometimes used public spaces to promote behavior and values by adorning classroom and school walls with value-related messages or by interrupting instruction for collective rituals. We saw that socialization messages were also conveyed in the stories and lessons of the formal curriculum and in the routine practices of classroom life, from standing in line to working in group projects to taking tests, that make up the "hidden curriculum" of schooling. Most schools also required students to participate in at least a few schoolwide programs related to behavior and values. Consequently, we expanded our data collection to include an analysis of socialization messages conveyed at several levels of classroom and school organization.

\section{THE SCHOOL SOCIALIZATION STUDY}

Our analysis grew out of a study conducted in 64 classrooms in southern California during the spring and fall of 1998. Follow-up surveys on the use of classroom time were conducted in late 1999 and early 2000. The setting of the study in southern California is important, since some practices that are characteristic of the schools we studied, such as the use of token economies to encourage conformity, may not be as prevalent in other states or regions.

\section{Data Collection}

We collected data using three methods: classroom observations, interviews with teachers and principals, and reading of curricular and program materials.

Classroom Observations For each of the 64 classrooms, we observed interaction for one hour during the school day at a time when whole-class instruction was occurring. So as not to bias teaching behaviors, we did not tell the teachers that we were interested in socialization messages; instead, the letters inviting teachers to participate indicated that we were interested in "patterns of classroom interaction." During the period of observation, we coded every socializing message the teachers communicated to students on code sheets listing 16 values and six classroom contexts in which values are conveyed. The values categories can be thought of as divided into four areas: (1) values connected to work performance (orderliness and industriousness), (2) values connected to interaction between self and others (respect for others, participation, cooperation, self-control, and self-direction), (3) "traditional virtues" (honesty, fairness, considerateness, responsibility, reliability, and courage), and (4) "modern values" (appreciation of cultural diversity, appreciation of one's own culture, appreciation of individual uniqueness and special talents, and appreciation of choice and variety as values). We characterize these values as modern values because they do not address generally approved character traits, but instead the value of a wide range of different abilities and contributions.

We report descriptive statistics on our observational data. However, because the observational data are subject to certain minor variations across raters, ${ }^{3}$ our discussion emphasizes the rank-order differences and 
the relative magnitudes of difference among the values coded, rather than the precise number of messages in each of the 16 value categories and six classroom contexts. We have a high level of confidence in the rankorder and relative magnitude differences that we found.

Interviews Following the observations, we conducted interviews with each classroom teacher and later with each school principal. During the interviews with the teachers, which lasted approximately one hour, we explained our interest in the schools' role in socialization. In addition, we asked the teachers to refrain from discussing the study with their colleagues and asked all new interviewees whether they had discussed the study with their colleagues. None of the 64 teachers in the sample said that they had discussed the study with their colleagues. In the interviews, we also asked the teachers to tell us about the rules and incentive systems that they used in their classrooms; the frequency with which issues related to respecting others, working hard, fairness, and honesty came up in their classrooms; how they dealt with problems in these areas; other values they considered to be important and how they incorporated these values into their teaching practices; the relationship of the formal curriculum to the teaching of values and behavioral ideals; the impact of multiculturalism on classroom practices; and the role of schools in preparing students for citizenship. Follow-up surveys asked the teachers to estimate the time they spent on various types of instructional activities, such as group work and whole-class instruction, during an average school week. The interviews with the principals focused on formal schoolwide programs and the principals' perceptions of change in the priority attached to the schools' role in socialization by parents and public officials.

Curricular and Program Materials We analyzed the content of the literature and social studies textbooks used in the schools we studied because these texts included a large proportion of the value-relevant messages found in the formal curriculum. In addition, we collected information on school programs aimed at influencing or reinforcing behavior and norms of conduct, ranging from school assemblies at which students were recognized for behavioral conformity to conflict resolution curricula used in most of the schools. We also collected information on required professional development programs, notably those aimed at developing cross-cultural awareness among teachers.

School Sites We conducted observations and interviews at four primary schools in two school districts, which we refer to as "District $A^{\prime \prime}$ and "District B." District A is composed primarily of two predominantly working-class cities with a large number of Spanish-speaking families. The school district is 49 percent Hispanic and under 30 percent non-Hispanic white. It includes a large proportion of families who qualify for state subsidies; 78 percent of the students are on reduced-price or free lunch programs. The four District A schools that we studied closely reflected the district's overall demographic profile.

In contrast, District B includes several predominantly non-Hispanic white and middleclass communities. The school district as a whole is 31 percent Hispanic and 49 percent non-Hispanic white. The four District $B$ schools in our study had a lower Hispanic population (an average of 28 percent) and a higher non-Hispanic white population (an average of 51 percent) than did the district as a whole.

We also conducted observations and interviews at two private schools in a third community. Both private schools were academically selective and were attended primarily by the children of professionals and executives.

Data were collected from second- and fifth-grade classrooms. These two grade levels allowed us to examine how socialization changes as children move from lower to upper grades. We chose them so as to avoid transition grades. Altogether, we collected data from 60 public school classrooms-15 classrooms in each grade in each districtand four classrooms, two in each of the two private schools.

The classrooms and schools we visited were more similar to one another than we expected. Only a few bivariate associations by 
type of school, community composition, and grade level were statistically significant. ${ }^{4}$ We did not, for example, find demands for order and conformity to be more common in the working-class schools of District $A$ than in the more middle-class schools of District B. Nor did we find encouragement for self-direction and autonomy to be more common in District $B$ than in District A. These findings lead us to doubt Bowles and Gintis's (1976) thesis that working-class children are socialized to conform to authority while middleclass children are socialized to exercise selfdirection. Expectations for high levels of order, attentiveness, and hard work were pervasive in the classrooms of both working-class and middle-class schools. Sociologists have shown that the instructional practices and academic expectations of schools often vary by schools' social-class composition (Anyon 1980, 1997; Carnoy and Levin 1985; Rubinowitz and Rosenbaum 2000). These findings may apply less well to behavioral expectations and values. In their expectations about behavior and values, the schools we studied would best be characterized as middle-class environments (see also Lareau, 1989)..$^{5}$

\section{SOCIALIZATION MESSAGES IN CLASSROOMS}

In this section, we provide evidence on the socialization messages conveyed at five levels of classroom and school organization: (1) through teacher-initiated interactions and the classroom rules framing these interactions, (2) through the subject-matter curriculum, (3) through routine practices embedded in everyday classroom life, (4) through students' participation in schoolwide cocurricular programs, and (5) through the use of public space in visual displays and oral and verbal rituals.

\section{Classroom Interaction}

Socialization messages are conveyed most directly through interaction in the classroom. Framing this interaction are rules that are intended to identify behavior that is permissible and desirable from behavior that is imper- missible or undesirable as defined by the teachers. Our observations of classroom interaction indicate that the great majority of teacher-initiated socialization messages have to do with orderliness and effort-in other words, with the operational foundations of work performance.

We coded an average of more than 18 teacher-initiated interaction messages per hour of observation. Approximately three out of four of these messages were related to orderliness in the classrooms (see Table 1). These messages reflected the teachers' efforts to quiet the students, to keep them from answering questions without recognition, or to redirect their straying attention to the task at hand. In these classrooms, the teachers frequently quieted students and controlled their movements with observations, such as "you can't be talking and working at the same time."

The next most frequent messagesapproximately one out of seven-had to do with work effort. They included teachers' mentions of the students' need to stay on task, finish on time, work faster, and the like. Specific students and entire classes were repeatedly told that they "should be busy." The teachers frequently noted, "I don't see [student's name] working." In two-fifths of the classrooms, the only messages we coded during our hour of observation had to do with orderliness and work effort. No other behaviors or values began to approach these two in frequency. These findings support the conclusions of sociologists who have argued that schools as performance-oriented bureaucracies have fundamental interests in order and effort (see, e.g., Cusick 1992; Lortie 1975; Waller 1932). Schools are the first performance-oriented bureaucracies that children encounter, and the great emphasis on orderliness follows directly from their interest in coaxing effort out of "immature workers" in settings where opportunities for distraction are great. 6

The next most common messages concerned the regulation of the self and the self's relation to others. In this category, we included messages related to respect for others, participation, cooperation, self-control, and self-direction. These messages have to do 
Table 1. Behavior and Value References in One-Hour Observations of 64 Primary School Classrooms

\begin{tabular}{|c|c|c|}
\hline Reference Category & Percentage of Total & $N$ \\
\hline \multicolumn{3}{|l|}{ Basic Organizational Controls } \\
\hline Orderliness & 71 & 839 \\
\hline Industriousness, hard work & 13 & 147 \\
\hline \multicolumn{3}{|c|}{ Regulation of Self and Self's Relation to Others } \\
\hline Respect, considerateness & 3 & 38 \\
\hline Participation & 3 & 38 \\
\hline Self-direction, autonomy & 3 & 29 \\
\hline Cooperation & 2 & 21 \\
\hline \multicolumn{3}{|l|}{ Traditional Moral Virtues } \\
\hline Fairness, justice & 1 & 15 \\
\hline Responsibility & 1 & 12 \\
\hline Self-control & 1 & 11 \\
\hline Courage & .9 & 10 \\
\hline Honesty & .6 & 7 \\
\hline \multicolumn{3}{|l|}{ Modern Values } \\
\hline Individual uniqueness & .4 & 4 \\
\hline Choice, variety & .3 & 3 \\
\hline Respect for group differences & .3 & 3 \\
\hline Respect for own group culture & .2 & 2 \\
\hline
\end{tabular}

Note: Total references $=1,179 ;$ references per observation period $=18.4$.

with how others are to be treated and the conditions that require the self to engage others as opposed to acting in its own right. Teachers are interested in helping students control their impulses in ways that allow them to work well with others and, at the same time, to learn to make choices for themselves about how to use their time and solve problems.

A few teachers paid special attention to these issues. Thus, in one second-grade classroom in District $A$, the teacher encouraged particular students to participate in the discussion by asking them to describe a character in the story the class was reading and emphasized the need for self-direction in managing time and completing work. "You can either keep going or you can stop. You choose," she said to one student. To another student, she said, "You can either draw checks or circles. It's your choice." Other teachers praised students for solving problems by themselves without asking for help and asked students to help others if they had finished their own work. Each of the values related to the regulation of the self and the self's relation to others accounted for approximately 2-3 percent of all the socialization messages that were coded. These messages are comparatively common in primary school classrooms because many children are inclined to follow their personal predilections and need cues about the conditions under which they are expected to act with others and to act alone.

The third most common messages concerned traditional moral virtues, including messages about fairness, responsibility, perseverance, courage, and honesty. Each of these values accounted for approximately 1 percent of all the socialization messages that were coded. The teachers were particularly interested in encouraging the students to take responsibility for their actions and to persevere even in the face of difficult work. They were also interested in helping students to take responsibility for solving issues that came up in the classroom-for example, to help resolve conflicts in the classroom. One teacher in District A observed, "Even these second graders need to learn to be responsible for bringing in their homework and for 
the consequences of their actions." One teacher in District B said, "Fifth graders learn a lot of new concepts, and it can be difficult for students who have learned easily up until then, so it's important to . . . persevere, but don't be too hard on yourself. Don't give up." Issues of honesty and fairness rarely emerged during our classroom observations because discussions about honesty and fairness tend to be provoked by specific events, and these events do not occur every day. In the interviews, the teachers said that incidents related to stealing, cheating, or conflict over perceived favoritism came up periodically during the year and were addressed when they arose.

The least frequent messages had to do with modern values, including the values of individual uniqueness and special talent, cultural diversity, choice, and variety. These modern values accounted for well under 1 percent of all the socialization messages that we coded. The values of individual uniqueness and cultural diversity were more likely to come up during specific occasions in the school year than during an ordinary day. If the students were studying about immigration in social studies, for instance, this topic naturally gave rise to discussions about the contributions of different ethnic groups. Stories about exceptional persons often encouraged the teachers to mention the importance of individual uniqueness. In one class, for example, students were reading about the jazz trumpeter Wynton Marsalis, and this story elicited several remarks from the teacher about the special talents of individuals. The teachers were certainly not opposed in principle to modern values, but they had little occasion to bring them up during an ordinary classroom instruction period.

We observed only a few instances-fewer than six in the 64 classrooms-in which the teachers broke away from their instructional focus to discuss moral or behavioral issues. One such discussion had to do with a cheating incident and another with an altercation on the soccer field. Instead, most of the socialization messages were delivered as a running commentary in the context of instructional activities. Thus, the general flavor of classroom life is similar to that of a coaching session in which the coach peppers in comments on the level of individual and group attention and effort as she or he provides instruction on a specific skill. In classrooms, as in coaching, these comments contribute to the pacing of the class, as well as to its moral tone. Many comments about values consisted of brief slogans, such as "Be the captain of your own ship!" and "Go the extra mile!"

Socialization messages tended to be delivered in a neutral manner of mentioning or directing, rather than of criticizing or praising particular students. Mentions of and directions concerning behavior and values were three times more common than either criticism or praise (see Table 2). Many teachers told us that criticism and praise were not necessary because "students know the rules." However, it seems likely that in the inclusive

Table 2. Context of Socialization Messages in 64 California Primary School Classrooms

\begin{tabular}{lcc}
\hline Context & $\begin{array}{c}\text { Percentage of Total Marks } \\
(N=1,179)\end{array}$ & $\begin{array}{c}\text { Percentage of Total Marks } \\
\text { Excluding Marks for } \\
\text { "Orderliness" } \\
(N=340)\end{array}$ \\
\hline Teacher mentions & 56 & 50 \\
Teacher criticizes & 18 & 14 \\
Teacher praises & 15 & 21 \\
Classroom ritual & 8 & 4 \\
Classroom discussion of issues & 2 & 6 \\
Discussion of stories, lessons & 2 & 4 \\
\hline
\end{tabular}


environment of the school, praise may also be avoided for its tendency to create resentment among the nonfavored majority against the favored few, while criticism may be avoided for its tendency to encourage alienation among the nonconforming few against the conforming majority.

The written rules framing interaction in the classroom also emphasized operational fundamentals related to orderliness and work performance. Every teacher had a set of rules that he or she used to set behavioral guidelines. Most teachers posted these rules on their classroom walls, along with lists of the rewards for good behavior and the consequences for misbehavior. The two domains of classroom life that were the most likely to be covered by these rules were "respect for other students" and "following directions." Rules in these domains were found in approximately two-thirds of the classrooms. The next most common rule domain, found in one-third of the classrooms, concerned work effort. Rules in this domain included "do your work on time," "do all your homework," and "do your best work." In addition, approximately onequarter of the classrooms had rules requiring students to "respect school property," "respect teachers and principals," or "work quietly." Thus, the six areas most commonly addressed by classroom rules all had to do with operational fundamentals as seen from the perspective of the school authorities: order, work effort, and compliance with school authorities.

\section{The Subject-Matter Curriculum}

The subject-matter curriculum is a second organizational level of schooling in which socialization messages are embedded. Not all curricular materials are strongly inscribed with socialization messages; even in language arts and social studies, many materials are directed less to teaching values than to providing information or awakening a sense of curiosity about the world. Thus, stories may give information about interesting and unusual occupations, such as movie director or environmentalist. They may seek to create a sense of wonder and interest in learning about outer space or unusual animals, for example. Or they may help students understand the world by, for instance, discussing how people find their way around a city.

At the same time, it is clear that many value-related messages are incorporated into the language arts and social studies curricula. Our content analysis of the language arts and social studies texts used in the two districts indicated that approximately three-quarters of the stories and lessons included value-relevant messages. It is here that both traditional virtues, such as persistence and responsibility, and modern values, such as appreciating cultural diversity, come most explicitly into play in the life of the classroom.

The value messages found in the language arts and social studies curricula were a blend of the new and the old. All the second-grade texts included many messages that encouraged the students to recognize that people have different special talents, that the country is made up of people from many different backgrounds, that it is important to understand and to appreciate these different cultures, and that we all depend on other people and should learn to work together in a cooperative spirit. In addition to emphasizing these modern values, the second-grade literature texts also included many messages connected to such traditional virtues as the rewards of hard work, persistence, and courage in the face of hardships. These messages were frequently found in adventure stories, such as Survival at Sea. The same mixed set of values appeared as dominant themes in the fifth-grade literature text adopted by both public school districts.

In contrast, the fifth-grade social studies text adopted by both districts provided a relatively conventional treatment of American history from the period before European settlement through the Civil War. Themes related to diversity and tolerance, the ways of life of different peoples, and the importance of interpretation from multiple points of view were certainly apparent in sections of this text. Yet these themes received less attention than did technological changes, trading relations, social customs, and defining historical events that are presumed to be important to all Americans. In the chapters on colonial America, for example, the text included such 
standard topics as witchcraft in Salem, trade in New England, the Stamp Act, and the ratification of the Constitution.

The appreciation of cultural diversity also came up at times in classroom projects and holiday celebrations. Most teachers in the sample, at a minimum, assigned a project requiring students to trace and discuss their ancestry. Many posted maps with pins representing the ancestral homes of students in their classrooms. Holidays have become an important vehicle for celebrating cultural diversity. Martin Luther King's birthday and Cinquo de Mayo serve as opportunities to discuss the achievements of African Americans and Mexican Americans. Most schools now celebrate cultural diversity during the Christmas season as well; the old sentiments of "peace on earth and goodwill to men" have become an entry way to a new outlook, "goodwill to cultures." At Halloween, some teachers ask students to bring in ghost stories from their families' countries of origin. Several of the schools celebrated a separate "International Day" in which ethnic dress and food were featured.

Teachers have many reasons for wanting to encourage students to appreciate their own cultures and those of their classmates. One fifth-grade teacher in District B observed, "I've had some Hispanic students [who] would denigrate their own culture . . . who saw Mexican culture as something they want to escape from and not understand." Another said: "It is important to show students not to be afraid of difference. When I taught sixth grade, each student did a report on a different country and prepared some food from that country. They may have thought the food from other countries was strange at first, but trying different things led them to appreciate them more."

Multiculturalism has become so dominant an aspiration in these classrooms that the term is often applied to stories and lessons with traditional themes simply because the main characters are girls or members of minority groups. Some teachers in our sample, for instance, described as "multicultural" both a story about an African American girl who perseveres, in the face of the resistance of her peers and teacher, to play Peter Pan in the class play and a standard assimilation story about a Chinese girl who feels the tension between her Chinese culture and her new American life. This mislabeling suggests that the multicultural orientation of contemporary primary schools is indistinguishable in many ways from the schools' long-standing commitments to achievement and assimilation. Traditional themes remain important, even if they are sometimes mislabeled by teachers as reflecting commitments to cultural diversity.

\section{Routine Classroom Practices}

In discussions of classroom socialization, the term the hidden curriculum has been used to describe the routine, embedded practices of classroom life that shape children's orientations in ways that are consistent with the demands of adult life. These practices are a third organizational level in which socialization messages are embedded. This curriculum is said to be hidden because, unlike the subject-matter curriculum, it directs students' attention through invisible means, rather than through overt and explicit instruction. Because they are not explicitly stated, the value orientations encouraged by the hidden curriculum must be inferred. Yet there can be little doubt that orientations to the world are shaped as much or more by daily repetition as by didactic practices and exhortation (see, e.g., Bourdieu 1979).

The elements of the hidden curriculum emphasized in classic studies by Dreeben (1968) and Jackson (1968) continue to be important features of schooling. Children still learn the values of individualism and achievement in their daily assignments and frequent evaluations. Children still learn patience from waiting in line for lunch and recess or to drink from a water fountain, and they still learn to cope with evaluation by the constant testing they encounter in the classroom. At the same time, our observations and discussions with teachers suggest that the hidden curriculum of schooling has expanded. In this section, we call attention to three increasingly important routine features of schooling: (1) token economies, (2) group projects, and (3) activity centers and rotations. 
Token Economies The classrooms we studied no longer rely exclusively on obedience to the teachers' authority to gain compliance. Instead, they also rely on symbolic rewards that are convertible into material goods, distributed through a token economy, to encourage approved forms of character and conduct. Strikingly, every teacher in our sample but one used such incentive systems, based on token economies, to motivate desired behavior. In exchange for doing their work on time, keeping out of trouble, and following class rules, individual students and table groups were given points, marbles, stickers, or other tokens that they could eventually trade in for candy, pizza, or class parties. Teachers say that these rewards help them to recognize every student in their classroom "for something" at least several times a month.

Although these token economies directly reflect the importance of behavioral psychology as a control strategy, we believe they ultimately reflect the significance of material rewards and the market economy in American society. Several schools made the connection explicit, by handing out "Greenbucks" or "Scholar Dollars" that could be accumulated and exchanged later for merchandise. Some teachers explicitly set up a game environment in which the students were "paid" for performing well and "paid" the teacher if they broke a rule. At the end of the week, the totals were counted, and if anyone reached a certain level, the teacher brought in ice cream and candy for all. Rewards, said one second-grade teacher, "are something they get excited about and [are] something they can share with their family."

Group Projects Group projects, activity centers, and rotations reflect another new condition of classroom life: The isolated learner in a regimented classroom is no longer the most common presence in school. Group activities played a significant role in the majority of the classrooms we visited. During a school week, table groups of four to six students may discuss their journal entries together, help each other with a difficult exercise, or design and execute a science or social studies project together. For the average teacher in our sam- ple, group learning activities accounted for nearly 20 percent of the instructional time during a typical school week, higher than the amount of time spent on individual seat work. Indeed, only whole-class instruction (accounting for 25-30 percent of the weekly instructional time for the average teacher in our sample) ranked higher in use as an instructional strategy.

Group activities encourage some students to receive the support they need from peers, rather than authorities, and allow other students to develop leadership skills. Many teachers see the need to work cooperatively as being explicitly linked to the work that students will be doing in later life, and some see collateral advantages as well. One fifth-grade teacher in District B said, "I tell them they will have to do this in the future ... work with all different kinds of people. . . I ask them: 'How do you think adults are able to work with their peers?"' Another fifth-grade teacher observed, "A lot of other things are interrelated [with group work], including developing integrity and appreciation of individual differences."

Activity Centers These teachers also adopted instructional strategies that increased variety and choice during the school week and associated increased variety with higher levels of student engagement. "You have to keep things moving," said one fifth-grade teacher in District A, "or you are going to lose many of them." Activity centers played a role in three-quarters of the classrooms we studied. These centers are places in the classroom that students can choose to go when they have finished their assigned work or through which they can rotate as part of the normal instructional day. The computer may be one activity center; the art table another. A third activity center may be set up to ask students to solve a challenging logical puzzle. In the classrooms that used activity centers, the teachers reported that an average of just over 10 percent of the instructional time during the week was spent in these centers.

Rotations Some schools also introduced variety into the classroom through rotations. During rotations, students from one class- 
room move to the classroom of another teacher who is the school's expert on a particular subject matter-often science, art, or music in which specialized talents are at a premium. In our sample, approximately half the teachers said that their students participated in rotations, usually for only a small part of the instructional week. Even this limited use of rotations is high when compared to the one-teacher-per-class norms of the past.

Nor were these the only ways in which these schools communicated the values of variety and change. To provide students with varied instructional settings, nearly every teacher in our sample also incorporated work in the library and/or computer lab into his or her weekly schedule. In their reading assignments, the teachers also tended to move quickly between genres as a means of increasing variety. Language arts textbooks included a highly varied set of materials, all in relatively short snippets. Units might include a short poem, a news story, a short story, a folk tale, or a scene from a play to perform, but lengthy works were not in evidence.

Like the routines emphasized by early investigators of the hidden curriculum, these new routine practices-token economies, group projects, activity centers, and rotations-encourage distinct orientations to the world and are consistent with the demands of contemporary adult society. Token economies encourage utilitarian motivations and reflect the increasing importance of material incentives as a form of social control. Group projects encourage comfort with collaboration and reflect the increasing collaborative character of work in many middle-class occupations. Activity centers and rotations encourage outlooks favorable to variety and choice and the capacity to move easily between many fast-changing activities. These outlooks are consistent with the fast-paced, multiple task environments that many middle-class adults face in their jobs and with the symbolic environment of mass entertainment and marketing.

\section{Schoolwide Programs}

Schoolwide programs are a fourth level of school organization in which socialization messages are embedded. The values associated with the schools' efforts in this area reflect a management philosophy that encourages every student to feel a sense of identification with the school and at the same time attempts to maintain order and minimize conflict among students.

The schools used a number of means to encourage a sense of inclusiveness through identification with the behavioral ideals of the school. All the schools provided gift certificates (usually at local supermarkets or restaurants) for students who were nominated by their teachers for exemplary conduct. These certificates were distributed at school assemblies. Six of the eight public school principals said that every student in the school would be recognized "for something" at some time during the year. All the principals emphasized the importance of public recognition for building the self-esteem of students, but it seems likely that creating a sense of identification with the school is even more important as a means of promoting the academic goals of the school and as a way of reducing the number of potentially alienated students. Half the schools provided additional rewards for students who were "caught doing good" by a staff member at any time during the day. These rewards included first-in-line-for-lunch passes, tickets redeemable for prizes, and "caught-doing-good" pencils. A variety of colorful names have been adopted for school programs that reward heroes and heroines of conduct: "Tigerrifics," "Lion's Pride," "Thumb's Up," and the like.

If the ideals of participation, respect, and self-esteem were promoted by programs aimed at maximizing students' involvement with the schools' behavioral ideals, other formal programs were used to minimize trouble. All the schools we studied controlled behavior outside the classroom with sanctions as well as rewards. These sanctions were based on a formal set of schoolwide rules barring taunting, physical violence, and the presence of dangerous substances and weapons on school grounds. All but one of the public schools had adopted a formal conflict resolution program, such as "Peace Path," "Peacebuilders," or "Resolving Conflict Creatively." In addition, all the schools partic- 
ipated in a state-sponsored drug education program, known as DARE (Drug Abuse Resistance Education), and all the schools offered "pull-out" counseling programs for students who were identified as being troubled by family, social adjustment, or behavioral problems. The importance of these programs to the schools can be measured by their costs. Each of these programs required extensive teacher training, and each cost the schools several dollars per student.

The principals said that they felt compelled to offer inclusiveness programs and conflict resolution programs because many students were perceived to be unprepared to interact peacefully in the ordered environment of the school. One principal in District A said: "We do have a problem. Children respect each other less and less, and parents are too busy to get involved. When they are asked to intervene, they say, 'I don't have time.' We've had to pick up the pieces. ... [The parents] work all day. They're tired, and they don't want to have to deal with discipline." Another principal said: "Look at some of the parents we have. They come home at night and say, 'I can't be responsible to feed or take care of children because I'm too stressed.' The neglect of parents like these [is] hindering their children. . . . It's a huge frustration for the schools and ... sad for all of us." Conflict resolution programs are directly related to the basic organizational interest of the schools in maintaining an orderly environment. From the principals' perspective, other available programs (such as character education curricula) can appear, by contrast, to be unnecessary "frills."

\section{Uses of Public Space}

Socialization messages can also be embedded in the uses of public space through visual displays or oral rituals. In the schools we studied, these means were used only infrequently. This low level of use may reflect the desire of schools to avoid public displays of value commitments that may offend parents or taxpayers who are interested primarily in academics or that may encourage cynicism among students.

Apart from the widespread practice of posting classroom rules, few walls were adorned with images and messages that were concerned with values. A small number of classrooms featured pictures of famous Americans who were women or members of minority groups. One room included pictures of athletes and words associated with the values of sports, such as determination, sportsmanship, courage, and resilience. In addition, principals at two of the schools said they occasionally hung banners on the school grounds that focused on values, such as responsibility and respect, which were illuminated with familiar cartoon characters. Only one school included value messages on the pencils, pins, cups, and T-shirts it sold to students and parents for fund-raising purposes. This school decorated pins with "PRIDE Paws," with "PRIDE" standing for "personal responsibility in daily efforts." This slogan was the school's emblem; it appeared on the school's awards and was, according to the principal, "talked about all the time." Two other principals said that they had included such messages in the past. Instead of attempting to instill adult values, some of the schools appealed to peer values. T-shirts for one school, for instance, were decorated with the motto: "Where the cool go to school."

The few oral and verbal rituals connected to socialization tended to encourage deference to authority more than any other behavior or value. Students at all the schools were required, for example, to be quiet during daily announcements by the principals over the public address system. Students stood at attention for daily flag pledges, and many teachers used ritual means of maintaining quiet, such as sounding a bell or raising an index finger. One fifth-grade teacher in District A called out the word "Salami" (short for "Stop and Look at Me") when he wanted students to pay attention to him. Only a few classrooms and schools engaged in active efforts to build a value consensus through verbal rituals. Two schools used a chant that the students were asked to repeat on occasion in classes and assemblies. One of these chants was called the "Jag Code" (for the school's jaguar mascot): "I am respectful, I am prepared to learn, I take responsibility." The other was, "You can do it if you put your mind to it." 
The schools' relative restraint in using public space to promote values may encourage the sense among some critics that schools are doing little in the area of socialization. Uses of public space, after all, are highly visible to outsiders. But this view overlooks the volume and range of socialization messages that are found in every other arena of classroom and school life.

\section{INFLUENCES ON SCHOOL SOCIALIZATION MESSAGES}

In this section, we present an analysis of the sources of the socialization messages we found in these 64 classrooms. This analysis emphasizes three themes. The first theme concerns the centrality of the underlying organizational interests of schools. The second theme concerns the ways in which social forces can influence the schools' repertoire of socialization messages. In particular, our analysis suggests two ways in which societal values may enter the school: through social movement activism institutionalized by the state or through the changing expectations of students and their parents based on changes in the organization of adult middleclass lives. The third theme concerns the organizational shaping of these environmental influences. When new values enter the school, they are, we believe, in every case refracted through the prism of the schools' underlying organizational interests.

\section{The Centrality of the Schools' Organizational Interests}

The organizational interests of schools are shaped by their purposes and the major challenges that schools face. Schools are production-oriented bureaucracies whose clientele are not yet mature and who represent a mix of backgrounds and personality types. These immature and heterogeneous students must work in group settings where distractions loom large. The schools have had long-standing interests in maintaining order and minimizing trouble, derived both from their production orientation and from the immaturity of their clientele. The schools' emphasis on energetic and persistent hard work follows from the underlying purpose of schoolingthe transmission of school knowledge in a fashion as efficient and effective as these conditions of instruction allow.

In recent years, schools have developed new interests. Clearly, schools were not always interested in celebrating the contributions of every single student to the classroom and school community. Indeed, in the past, disinterested and marginal students were actively discouraged from continuing with their schooling (Tyack 1974; Tyack and Hansot 1982). In all likelihood, as students spend more years in school, schools experience greater incentives to encourage the commitment of all students. In addition, the philosophy of progressive education (which arose, not incidentally, at a time when secondary schooling was becoming the norm) helped to convince educators that the interest of students must be captured, rather than commandeered. This philosophy has led to an increasing emphasis on finding ways to avoid boredom in the classroom. Schools also developed interests, over the course of recent generations, in creating a sense of identification between all students and the school community. In part, such identifications help to reduce alienation and therefore the potential for trouble. In part, they may also be valued as a means of improving the achievement orientation of socially or academically marginal students.

Many of the socialization messages expressed most frequently in our study reflect this set of historically developed organizational interests. The classroom interaction data are well explained by the schools' long-standing priorities on the maximization of order and industriousness. Schoolwide conflict resolution programs reinforce these values while responding to a perceived decrease in parental discipline. The emphases on variety and choice we found in classroom practices reflect the newer priorities of schools in capturing the interest of all students. The emphases in schoolwide programs on respect for others, participation, and building selfesteem reflect the schools' interest in encouraging identifications between students and the school community. 


\section{Sources of Societal Influence}

Not all the findings of the study, however, can be accounted for by an emphasis on the centrality of the schools' underlying organizational priorities. This is particularly true of many of the behavioral priorities and values we found in both the subject-matter curriculum and the "new hidden curriculum" of the schools we studied. To explain these findings, it is necessary to turn attention away from the organizational interests of the schools to examine the ways in which values originating outside the schools are incorporated by the schools.

Our analysis suggests that new values enter the schools in one of two ways: (1) through the successful advocacy of social-movement and educational activists supported by governmental officials and (2) through the changing experiences and expectations of middleclass citizens as mediated by the popularity of new pedagogical philosophies. The values associated with multiculturalism are a good example of the first means by which new values enter the schools. Many of the values associated with the newer elements of the hidden curriculum, such as the use of token economies and group projects, are good examples of the second. We use these examples to illustrate the two processes through which we hypothesize that new values and behavioral priorities are incorporated into the schools.

Process 1: Educational Activism Institutionalized with State Support The background forces encouraging multiculturalism in the 1970s and 1980s are clear. One important factor is that the non-Hispanic white proportion of the population dropped from 90 percent to 75 percent between 1950 and 1990. In many urban centers, people of color now make up the majority or the near-majority of the population. Another important factor is globalization. East Asian, European, and North American firms are tied together through complex networks of joint ownership, joint capitalization, and franchising and licensing agreements. Financial markets have become fully internationalized among the wealthier countries, with changes in one stock exchange affecting the other major exchanges. Travel and tourism continue to grow as part of the global economy, and other forms of international exchange-from scholarly conferences to international peacekeeping forces-have also become commonplace. Continued global integration means the growth of trade and exchange in other regions of the world (see, e.g., Brint 1998).

These forces of demographic change and globalization created conditions favorable to multicultural, rather than monocultural, outlooks. However, to be successful, social movements must mobilize and become institutionalized. Multiculturalism was, in its early days, very much the child of the civil rights and feminist movements. Traditions of activism and generational conflict, which were carried over into the educational arena, played a critical role in its rise. As Gates (1992:19), the literary scholar and a participant in these conflicts, wrote: "Ours was the generation that took over buildings in the late 1960s and demanded black and women's studies programs and now ... has come back to challenge the traditional [curriculum]."

It is important to emphasize that educational movements are rarely successful unless they eventually receive the support of the state. In the case of multiculturalism, institutionalization occurred both informally and under the aegis of the state. By the late 1980s, many U.S. states (beginning with California in 1987) added principles in their curricular guidelines that required multicultural and gender-fair perspectives. By the mid-1990s, a near-majority of states had adopted such guidelines (Rosenfelt 1994).

Multiculturalism is not the only recent social movement to become incorporated into classroom socialization practices. The "character education" movement, although much less successful than the multicultural movement, has similarly been promoted by educational activists-indeed, partly as a reaction to the schools' emphasis on diversity - and it, too, has relied on governmental support in those states in which it has been most successful (S. Glazer 1996).

Process 2: New Practices Reflecting Changes in Middle-Class Lives If we take as a premise that in relation to values training, schools are 
essentially middle-class institutions, we can see how new features of the hidden curriculum may be connected to changes in the organization of middle-class adults' lives. Whereas the classic elements of the hidden curriculum prepared students for adult lives of individualist achievement and bureaucratic regulation, the new elements prepare students for a "dual society" that is organized along market and bureaucratic lines in its work activities and along entertainment and consumerist lines in its leisure activities. Classroom token economies are clearly connected to the dominant incentives offered by the surrounding market economy. Group projects are connected to the collaborative nature of much contemporary work, particularly in professional and managerial occupations. And, of course, the enjoyment of variety and choice are important features of the consumer economy.

We hypothesize that new routine practices typically enter the schools in the following way: As society changes, children and their parents develop new expectations. The schools find it advantageous to address these expectations in order to maintain commitment. Pedagogical practices that resonate with these expectations, therefore, have a greater chance of gaining a foothold in the schools than those that do not. Thus, broad social changes in the organization of middleclass lives are typically carried into classrooms through the popularity of pedagogical movements with which they show a close affinity. From this perspective, token economies may ultimately reflect the importance of market rewards in American life, but they are encouraged more immediately by the influence of behavioral psychology in contemporary educational philosophies. ${ }^{7}$ Similarly, the rise of joint and collaborative activities in adult work lives may be the ultimate condition from which new expectations of the importance of teamwork arise, but the popularity of "cooperative learning" philosophies is the immediate source of the schools' recent emphasis on group learning opportunities.

\section{The Organizational Filter}

New ideas and values have a chance to become popular only if they fit or, at least, do not significantly threaten the organizational priorities of schools. Conflict resolution programs address issues that are close to the fundamental interests of schools in minimizing trouble, and they have consequently become more popular than many other programs that are potentially available to schools. Similarly, an emphasis on building self-esteem can help to make every student feel a part of the school community, another fundamental organizational interest in today's public schools. By contrast, the emphasis of conservative reformers on traditional values strikes a less resonant chord from the perspective of the schools' main organizational interests because this emphasis does not necessarily lead to the improvement of order, the minimization of trouble, or a more inclusive level of identification with the school community. ${ }^{8}$

Schools also tend to moderate the force of social activism in line with their interests in orderliness and getting all students to identify with the school. If one considers the range of ways in which multiculturalism could have been embedded in the schools, it is clear that it has been institutionalized only in a limited form. An extensive form of institutionalization may involve using multicultural material in all aspects of the curriculum. It may involve advocacy of the doctrine of cultural relativism or even of the doctrine of European whites as oppressors. (For a study of challenges based on such alternative forms, see Binder 2000.) It may also involve programs to address differences in the learning styles of members of different groups. In the classrooms we visited, it has meant none of these things. Instead, support for multiculturalism (and the underlying value of cultural diversity) has been expressed in one or two class projects a year about ethnic origins and minority achievers, a handful of stories and lessons about minority cultures or nonwhite characters, and cross-cultural holiday celebrations. ${ }^{9}$

In the limited form in which it has been institutionalized, multiculturalism is far from a divisive influence in the schools. Instead, it encourages an outlook of inclusiveness that fits well with the schools' desire to encourage all students to identify with the school community. Through multiculturalism, the ethnic and national-origin differences among stu- 
dents can be both acknowledged and reconciled with two other principles that are frequently expressed in contemporary school discourse-"everyone is special in his or her own way" and "underneath our differences, we share many things."

Under these circumstances, it would be surprising if a significant conflict existed in the schools between advocates of multicultural education and advocates of traditional values. And, in fact, we found virtually no evidence of such a "culture war" in our sample population. When we divided the 64 teachers into three groups-" "traditional-values conservatives," "multicultural liberals," and "combiners" - on the basis of their responses to all our interview questions, we found slightly more traditional-values conservatives than multicultural liberals, but 80 percent of the teachers fell into the group who were comfortable combining the two emphases. 10

\section{DISCUSSION}

In this concluding section, we evaluate the images of school socialization messages held by cultural conservatives and critical social theorists. We then describe a new way of thinking about school socialization messages that emphasizes not the conflict between traditional virtues and modern values, but the modification and blending of the two. We also discuss a problem we observed in the way values are communicated in the schools. This problem has to do with redefinitions of value concepts along lines suggested by the schools' organizational interests.

\section{The Blending of Old and New Messages}

Our analysis suggests that the advocacy of many traditional values has not been lost in today's schools. Such traditional virtues as hard work and responsibility continue to be at least as important as modern values of diversity, teamwork, variety, and choice. When we asked the teachers in our sample how they would rank the importance of seven frequently mentioned purposes of schooling, for example, they ranked "developing charac- ter traits like responsibility and hard work" higher on a 10-point scale than any other activity of schools, including "developing skills and knowledge in curriculum areas" (see Table 3). Moreover, demands for orderliness and work effort clearly continue to dominate teacher-initiated interaction with students in classroom instruction.

At the same time, it is fair to say that not all traditional virtues remain equally important in today's schools. Those who have lamented the decline in the teaching of values in American schools have usually been concerned with three sets of values that once found a prominent place in school readers and everyday instruction in the schools: (1) Judeo-Christian ethical values, which included honesty, fairness, kindness, considerateness, and concern for the less fortunate; (2) civic values, which included patriotism, bravery, law-abidingness, and participation in community and civic life; and (3) entrepreneurial values, which included industriousness, the wise use of time and resources, reliability, planning for the future, responsibility, and the capacity for self-directed activity. This cluster of values has been described as reflecting the significance of Protestant, republican, and entrepreneurial influences in the nation-building efforts of elites in 19th-century America (Meyer, Tyack, Nagel, and Gordon 1979; Tyack and Hansot 1982).

Assuming that this characterization is correct, the findings of this study suggest that certain virtues that have been historically associated with the entrepreneurial ethoshard work, responsibility, reliability, self-control, individualism, and self-direction-remain important in today's schools, but that JudeoChristian ethical virtues and republican civic virtues have declined in importance. These trends may reflect, as some have argued, the declining influence of the dominant status group of Protestant-republican nation builders on the ideas of school administrators and the rising influence of bureaucratic authority (Tyack and Hansot 1982). The decline of republican civic virtues may also reflect, to some degree, the movement from a "heroic" to a "prosaic" stage of nationalism in the United States and other advanced societies (Kamens 1992). 
Table 3. Teachers' Ratings of Selected School Priorities, by Level of Importance, on a 10Point Scale (percentage; $N=64$ )

\begin{tabular}{lccc}
\hline & & Rating & \\
\cline { 2 - 4 } & $\begin{array}{c}10 \\
\text { (High) }\end{array}$ & $8-9$ & $\begin{array}{c}7 \text { or Below } \\
\text { (Low) }\end{array}$ \\
\hline $\begin{array}{l}\text { Characteristic } \\
\begin{array}{l}\text { Developing character traits } \\
\quad \text { like hard work and responsibility }\end{array}\end{array}$ & 77 & 18 & 5 \\
$\begin{array}{l}\text { Developing knowledge and skills } \\
\text { in curricular areas }\end{array}$ & 63 & 31 & 6 \\
$\begin{array}{l}\text { Developing children's self-esteem } \\
\begin{array}{l}\text { Helping children to learn to } \\
\text { appreciate other people's cultures }\end{array}\end{array}$ & 59 & 33 & 8 \\
$\begin{array}{l}\text { Helping children to express } \\
\text { themselves well in written work }\end{array}$ & 50 & 31 & 19 \\
$\begin{array}{l}\text { Helping children to express } \\
\text { themselves orally }\end{array}$ & 44 & 50 & 6 \\
$\begin{array}{l}\text { Developing children's interests in } \\
\text { nonacademic curricular and } \\
\text { extracurricular activities }\end{array}$ & 36 & 52 & 12 \\
\hline
\end{tabular}

Although it is clear that teachers are active in maintaining order and work discipline in their classrooms, we are nevertheless skeptical of the portraits of the classroom "disciplinary regime" offered by some critical social theorists who have been influenced by the work of Foucault $(1965,1977)$. By concentrating exclusively on classroom restrictions and work demands, these critics miss both the indulgent qualities of today's classrooms and the range of other values conveyed in the schools. In the classrooms we studied, teachers maintained control with a light touch more often than not, and they were extremely sensitive to the role that schooling can play in damaging students' self-esteem. The modern primary school classroom, with its many activities, group projects, constant change, and frequent celebrations, can be described as a regimented space only by rigorously limiting attention to one part of the whole story.

What, then, would be a more accurate characterization? In the minds of most teachers, new values do not replace or compete with older values. For this reason, the dominant socialization ideology of the schools should be characterized neither as "traditional" nor as "modern" but, rather, as a blend of the two. It can be accurately described as "pluralist neotraditionalism" - pluralist because it embraces cultural differences, traditionalist because it endorses a number of traditional virtues, but neotraditionalist because some traditional virtues have lost prominence (see Table 4). The routine practices of classrooms similarly show a blending of the old and the new. The old world of bureaucratic organization and individual achievement clearly finds a place in these classrooms-universalistic standards, specialized competencies, and individual achievement are as important as ever. Yet new emphases on material rewards for conformity, group work, choice, and variety are also evident.

Our analysis shows further that different socialization messages are conveyed at different levels of classroom and school organization. Messages originating in the organizational priorities of the school are expressed primarily through teacher-initiated interactions, through the classroom rules framing these interactions, and through schoolwide programs. These messages emphasize order- 
Table 4. Elements of "Pluralist Neo-traditionalism"

\begin{tabular}{|c|c|c|}
\hline Pluralism & Neo- & Traditionalism \\
\hline $\begin{array}{l}\text { New interest in cultural } \\
\text { awareness in a diverse society }\end{array}$ & $\begin{array}{l}\text { Diminished Values } \\
\text { Judeo-Christian ethics }\end{array}$ & $\begin{array}{l}\text { Continued emphasis on } \\
\text { orderliness }\end{array}$ \\
\hline $\begin{array}{l}\text { New emphasis on the ability to } \\
\text { "get along with" people unlike } \\
\text { oneself }\end{array}$ & Civic-nationalist values & $\begin{array}{l}\text { Continued emphasis on } \\
\text { hard work, industriousness }\end{array}$ \\
\hline $\begin{array}{l}\text { New emphasis on ability to } \\
\text { cooperate with others on joint } \\
\text { projects }\end{array}$ & $\begin{array}{l}\text { Transmuted Values } \\
\text { Respect: from } \\
\text { kindness, politeness } \\
\text { to zones of } \\
\text { noninterference }\end{array}$ & $\begin{array}{l}\text { Continued emphasis on } \\
\text { responsibility } \\
\text { Continued emphasis on } \\
\text { the wise use of time and } \\
\text { resources }\end{array}$ \\
\hline & $\begin{array}{l}\text { Self-esteem: from } \\
\text { based primarily on } \\
\text { accomplishments } \\
\text { to based primarily } \\
\text { on support from } \\
\text { adults }\end{array}$ & $\begin{array}{l}\text { Continued emphasis on } \\
\text { self-discipline, self-control }\end{array}$ \\
\hline & $\begin{array}{l}\text { New Means of Control } \\
\text { Cognitive direction, } \\
\text { rather than praise and } \\
\text { criticism }\end{array}$ & \\
\hline & \multicolumn{2}{|c|}{$\begin{array}{l}\text { Token economy systems } \\
\text { as supplements to personal } \\
\text { control by teachers }\end{array}$} \\
\hline
\end{tabular}

liness, hard work, respect for others, and active participation. They reflect organizational priorities that have to do with the maintenance of order, the minimization of trouble, the encouragement of work effort, and the promotion of a sense of identification with the school by all students. Overlaid on these organizational priorities are value messages originating in the broader society that are expressed primarily through the subjectmatter curriculum and through the routine practices of everyday classroom life. These messages combine emphases on some traditional virtues, such as persistence in the face of adversity and personal responsibility, with such modern values as appreciation of cultural diversity and delight in variety and choice. For new societal values to be accepted by the schools, they must be consistent with the fundamental organizational priorities of the schools. Curricular emphases on cultural diversity are, for example, only one way to promote the schools' interest in inclusiveness, but they are consistent with these interests and can therefore be incorporated, provided that they do not threaten other fundamental priorities.

\section{The Organizational Redefinition of Value Concepts}

If there are problems with the socialization messages conveyed in contemporary schooling, these problems have little to do, we believe, with the decline of traditional moral 
messages or with a contest between traditional virtues and modern values. Instead, we would highlight an entirely different problem, one that is consistent with the organizational analysis we have proposed here. Because schools address behavior and values in ways that are strongly influenced by their organizational priorities, many distortions are possible in their interpretation and use of value concepts. In our study, we saw a number of examples of such distortions. Among the most significant examples were the schools' uses of the concepts of citizenship, selfesteem, and respect. We believe that societal understandings of these concepts have been influenced-not always positively-by the redefinitions given to them in the school environment. Using the concepts of citizenship, self-esteem, and respect, we present illustrations of what we mean by the schools' redefinition of value concepts and indicate why we think it is a problem.

Virtually every teacher we interviewed said that schools should be teaching good citizenship. When we pressed the teachers to discuss the meaning of citizenship, however, fewer than 15 percent mentioned the active side of citizenship_voicing views on public issues and participating in political life. Many more teachers gave school-based definitions of citizenship that emphasized "acting responsibly" and "getting along with others." Other frequent definitions of citizenship referred to "working hard" and "showing respect for others." Thus, the definitions of citizenship that most of the teachers gave were closely related to the schools' interests in maintaining order and work effort and minimizing trouble. Several teachers made this connection explicit: "It's important for public schools to develop respectful . . . hardworking citizens," said one fifth-grade teacher in District A."[At this school], students who are good . . - respectful citizens are given 'Good Bear' tickets." More troubling still were the 11 teachers who emphasized the most passive forms of citizenship: following rules; respecting authority; and believing in the laws, the government, and the Constitution. Thus, one second-grade teacher in District A said, "Yes, it's important for schools to help students become good citizens. Schools need to teach rules and that you have to follow the rules. . . . Schools [follow] guidelines. Students need to follow guidelines."

The most common school definitions of citizenship contrast sharply-and, in our view, inappropriately-with accepted definitions of citizenship in democratic political theory. These latter definitions emphasize attentiveness to public affairs and active participation in community and political life, including protest, when necessary, in addition to the specific obligations citizens owe to the state.

The great majority of teachers we interviewed thought that the development of children's self-esteem was an essential purpose of schooling (see also Meyer 1987). It is clear that most teachers no longer believe that selfesteem comes exclusively from meeting the challenges of the external environment. Nor, however, do they fully adopt the therapeutic model of self-esteem so often ridiculed by cultural conservatives - the view that self-esteem develops solely from regular attention to children's feelings, combined with strong and uncritical support from adults. Instead, teachers indicate some confusion about the relative importance of validating accomplishments; many think that meeting challenges is important to self-esteem but less important than feeling the support of others. Thus, at an extreme, a fifth-grade teacher in District B said, "When I concentrate on doing math, I don't get as far as when I concentrate on doing self-esteem and then doing math."

Again, we believe that the schools' interests have led to a subtle redefinition of an important concept. Schools have an interest in developing commitment among their students. As one consequence of this interest, many teachers now attempt to recognize every student "for something" at least a few times a month, and many principals attempt to recognize every student "for something" at least once during the year. Confidencebuilding activities and recognition "for something" may help to build a sense of commitment to the classroom community and the school, but they are less likely to help students build a durable sense of self-confidence than a mix of support and the successful accomplishment of challenging tasks.

Perhaps more than any other concept, 
respect has become the dominant ethical touchstone in contemporary schooling. It is used constantly by school authorities to describe how students are expected to behave toward one another. Only a few teachers, however, continue to emphasize considerateness, the just appreciation of the qualities of others or other ceremonial aspects of respect. One second-grade teacher in District B who did said, "I would like them to act kindly to one another, and I remind them what are appropriate things to say to a person, like 'please' and 'thank you.'. . . Consideration is very important, and it is one of the easiest traits to model."

Instead, for most teachers respect is the expectation that students will not taunt or bother others, will keep their hands to themselves, and will defer to authority. In this sense, the meaning of respect has also been redefined by the schools' organizational priorities; it has become another means of minimizing trouble and maintaining order. A second-grade teacher in District $B$ told us, for example, that "the issue of respect comes up continuously" in her class: "Students will be physical with each other, touching, kicking, hitting, taking up others' personal space." Because the term respect suggests qualities of considerateness and the just appreciation of others, its use allows the schools to attach an aura of thoughtful regard to their underlying interest in avoiding conflict. Terms like civilly minimal attention, zones of noninterference, and deference to authority would be more accurate than respect to describe the actual ethical expectations of many of today's schools.

\section{CONCLUSION}

The major contribution of this article has been to provide a framework for understanding the volume and content of socialization messages expressed in today's schools. This framework specifies five levels of classroom and school organization in which socialization messages are embedded. It links the behavioral ideals expressed at two of these levelsteacher-initiated interactions in the classroom and schoolwide programs-to the schools' interests in maintaining orderliness and work effort, minimizing trouble, and encouraging students to identify with the school. It links the values expressed at two other levels-the formal curriculum and the routine practices of everyday classroom life-to a blending of old and new cultural influences. The framework specifies two ways in which new values can enter the schools-through the influence of social movements that are institutionalized with governmental support or through the adoption of pedagogical philosophies that are consistent with changes in adult middleclass life experiences. This framework allows for a more comprehensive approach to the study of school socialization messages than has been possible thus far. At the same time, the specific findings reported here need to be validated on national or additional regional samples of classrooms and schools.

The second contribution of this article has been to raise questions about the images of school socialization found in the writings of cultural conservatives and critical social theorists. These two sets of critics focus on channels of socialization that best support their positions-the formal curriculum, in the case of cultural conservatives, and teacher-initiated interaction, in the case of critical social theorists. We find their conclusions one-sided even in relation to the channels they examine and, above all, incomplete because of their limited focus. The final contribution of this article is to draw attention to a problem of socialization in today's schools: the tendency of school authorities to define concepts, such as citizenship, self-esteem, and respect, to fit the organizational priorities of the school at the expense of older and more precise understandings of the terms.

\section{NOTES}

1. Reviewing these studies, the educational historian Tyack (1999:79) speculated that "the national [identifying symbolism] has been enlarged rather than abandoned." By this, he meant that new values, such as the appreciation of cultural diversity, have been added to traditional socializing messages emphasizing values like hard work and 
responsibility. But Tyack observed that the evidence was not yet in on the content and form of moral education in contemporary schooling.

2. These studies have an affinity with the work of an earlier generation of reformers who criticized the authoritarian tendencies of school socialization practices (see, e.g., Freidenberg 1959; Goodman 1960; Neill 1960). However, they are more concerned with power than with the issue that motivated earlier critics: the potential of schools to limit human potential.

3. Although we are confident of the rankorder differences we found, three limitations of the coding procedures should be noted. First, during observation pretests, we were unable to achieve complete interrater reliability. Messages that were coded by one rater were not always heard by another, and in a few cases, messages were coded differently by different coders. Second, because our observation periods focused on periods of whole-class instruction, they are not entirely representative of interaction during the entire day. Less than a third of the total class time was spent in whole-class instruction in most of the classrooms we studied. Finally, it is important to distinguish between the frequency and dramatic value of socialization messages. Some important socialization events are dramatic but are so rare that we were unlikely to catch them. For example, a class resolution of a cheating controversy may make an impression, but it may happen only once a year. Frequency has a certain weight, but so may the comparatively rare dramatic event.

4. The high-SES schools as a group were somewhat more likely to emphasize character and hard work than were the other schools. In one analysis, we grouped the two highestSES schools in District B with the two private schools and compared them to the other schools in the sample. The teachers in the high-SES schools were significantly more likely $(p<.05)$ to rank the teaching of character traits as a very important purpose of schools and to urge students to work harder in classroom interactions $(p<.10)$. They were more likely, but not quite at a statistically significant level, to say that issues of responsibility came up frequently in class. In addition, teachers in District $B$, the predominantly middle-class district, showed a greater tendency to emphasize the "modern virtues" of diversity and individual uniqueness $(p<.10)$. We interpret this finding as reflecting the teachers' desire to counter the possibility of insularity in middle-class communities and their greater commitment to encouraging the individual characteristics of students.

In District A, by contrast, more basic issues were at stake. In this predominantly workingclass district, some teachers said that they rewarded students for washing in the morning, eating their breakfast, and brushing their teeth. Because of the insecurity of the environment, the teachers in District A were more likely to warn against following the crowd in potentially dangerous activities. They were also more likely (though not by a statistically significant margin) to encourage students to take pride in their own group's culture.

Differences related to age were more apparent than were differences related to SES. It is not surprising that quite a bit more socialization work went into teaching second graders than fifth graders. The second-grade teachers were more likely to work on the confidence of their students, to help them avoid trouble, and to encourage them to develop a sense of responsibility. In addition, they were more likely to rank the development of selfesteem $(p<.05)$ and skills in oral expression $(p<.10)$ high as important purposes of schooling. These responses indicate that many second-grade teachers are concerned that their students do not learn habits of passivity that will be difficult to break in later years. The second-grade teachers were also more likely than the fifth-grade teachers to say that issues of following the crowd ( $p<$ $.05)$ and responsibility $(p<.05)$ came up frequently.

5. One school stood out as a clear exception to this generalization, however. We were struck by the amount of attention given to traditional moral education in the leading private school we visited. This school is self-consciously modeled along the lines of the "St. Grottelsex" boarding schools in New England. As in these schools, the teaching of values is an explicit, well-spelled-out, and highly institutionalized 
element of the school's mission and structure (Cookson and Persell 1985). The school's mission statement includes the following passage: "[E]ven greater than our concern for academics has been our determination to do a very oldfashioned thing, to build character in our children-to stress honesty, courtesy, responsibility, and a concern for others."

Our respondents described every teacher at the school as "highly aware" of this aspect of the school's mission. The school guaranteed this awareness most visibly through its required chapel talks. Each week a particular virtue (such as sportsmanship, punctuality, compassion, or honesty) took a turn as the topic of the week. On each day of the week, a student from one of the upper-grade classrooms gave a talk on that week's highlighted virtue. None of the public schools we visited remotely resembled this elite private school, where traditional moral instruction was thoroughly interwoven with the life of the school, most visibly in the daily chapel talks given by the upper-grade students.

6. The schools' interest in order and effort parallel those of employers and presumably contribute to the development of a disciplined labor force, as many historians and social scientists have emphasized (see, e.g., Bowles and Gintis 1976; Callahan 1962; Giroux 1981).

7. Other social factors, such as the exceptional diversity of the population, may also play a role in the popularity of token economies in southern California primary schools. Pure normative control may be more difficult to sustain in the face of high levels of cultural diversity.

8. The most popular of the "character education" programs, Michael Josephson's "character counts" curriculum, had been adopted, according to the Josephson Institute's estimate, in some $500-600$ communities by the mid-1990s (Healy 1996), well under 1 percent of the public schools in the country.

9. It is interesting that not one of the teachers in our sample expressed views consistent with the idea that all cultures are of exactly equal importance-a strong form of cultural relativism that some conservative critics consider to be prevalent in the schools.

10. The interviews included a number of questions addressing both sides of the values question. Several questions asked teachers to discuss their views of multicultural curricula and appreciation of cultural diversity as a teaching goal. Another question asked teachers to rate the importance of building children's self-esteem on a scale of 1 to 10 . Other questions asked teachers to rate the importance they attached to traditional values, such as responsibility and hard work, and how often they addressed issues like honesty, fairness, and respect for others in class. When teachers gave responses indicating a positive orientation toward both "modern" and "traditional" values, we classified them as combiners. When teachers indicated opposition to one set or the other, we classified them as either traditional-values conservatives or multicultural liberals. The teachers in these two latter categories tended to be critical of the perspective of those on the other side. For example, one traditional-values conservative said, "Teachers get down on teachers like me because our focus is the curriculum. I've seen teachers focus so much on self-esteem and building self-esteem . . . that they lose [the subject matter materials] that should be taught." One multicultural liberal, a fifthgrade teacher in District B, said, "We should$n$ 't be saying to students, 'We want you to become Americans' [because] being an American is many different things. . . . You have to be proud of who you are. . . People say they don't want to be judged because of race or ethnicity, but they are."

\section{REFERENCES}

Anyon, Jean. 1980. "Social Class and the Hidden Curriculum of Work." Journal of Education 162:67-92.

--. 1997. Ghetto Schooling: A Political Economy of Urban Educational Reform. New York: Teachers College Press.

Bendix, Reinhard. 1968. "The Extension of Citizenship to the Lower Classes." Pp. 233-56 in State and Society: A Reader in Comparative Political Sociology, edited by Reinhard Bendix, in collaboration with Conrad Brand [and others]. Boston: Little-Brown.

Bennett, William J. 1993. The Book of Virtues. New York: Simon \& Schuster. 
Bernstein, Richard. 1994. Dictatorship of Virtue: Multiculturalism and the Battle for America's Future. New York: Alfred A. Knopf.

Binder, Amy. 2000. "Why Do Some Curricular Challenges Work While Others Do Not? The Case of Three Afrocentric Challenges." Sociology of Education 73:69-91.

Bourdieu, Pierre. 1979. Outline of a Theory of Practice. Cambridge, England: Cambridge University Press.

Bowles, Samuel, and Herbert Gintis. 1976. Schooling in Capitalist America. New York: Basic Books.

Brint, Steven. 1998. Schools and Societies. Thousand Oaks, CA: Pine Forge Press.

Callahan, Raymond. 1962. Education and the Cult of Efficiency. Chicago: University of Chicago Press.

Carnoy, Martin, and Henry M. Levin. 1985. Schooling and Work in the Democratic State. Stanford, CA: Stanford University Press.

Cheney, Lynne V. 1987. American Memory: A Report on the Humanities in the Nation's Public Schools. Washington, DC: National Endowment for the Humanities.

--. 1990. Tyrannical Machines: A Report on Educational Policies Gone Wrong and Our Best Hopes for Setting Them Right. Washington, DC: National Endowment for the Humanities.

Collins, Randall. 1977. "Some Comparative Principles of Educational Stratification." Harvard Educational Review 47:1-27.

Cookson, Peter W., and Caroline Hodges Persell. 1985. Preparing for Power: America's Elite Boarding Schools. New York: Basic Books.

Cusick, Philip. 1992. The Educational System: Its Nature and Logic. New York: McGraw-Hill.

Dreeben, Robert. 1968. On What Is Learned in School. Reading, MA: Addison-Wesley.

Durkheim, Emile. 1961. Moral Education. New York: Free Press. [Original work published 1923]

Farkas, Steve, and Jean Johnson. 1996. Given the Circumstances: Teachers Talk about Public Education Today. New York: Public Agenda.

Farkas, Steve, Jean Johnson, and Tony Foleno. 2000. A Sense of Calling: Who Teaches and Why. New York: Public Agenda.

Fitzgerald, Frances. 1979. America Revised: History Textbooks in the 20th Century. Boston: LittleBrown.

Foucault, Michel. 1965. Madness and Civilization: A History of Insanity in the Age of Reason. New York: Pantheon Books.

--. 1977. Discipline and Punish. New York: Pantheon Books.

Freidenberg, Edgar Z. 1959. The Vanishing Adolescent. Boston: Beacon Press.
Frisch, Michael. 1989. "American History and the Structures of Collective Memory: A Modest Exercise in Empirical Iconography." Journal of American History 75:1142-55.

Gates, Henry Louis, Jr. 1992. Loose Canons: Notes on the Culture Wars. New York: Oxford University Press.

Giddens, Anthony. 1984. The Constitution of Society. Berkeley: University of California Press.

Gilbert, Dennis A. 1988. Compendium of American Public Opinion. New York: Facts on File Publications.

Giroux, Henry A. 1981. Ideology, Culture, and the Process of Schooling. Philadelphia: Temple University Press.

Glazer, Nathan. 1997. We Are All Multiculturalists Now. Cambridge, MA: Harvard University Press.

Glazer, Sarah. 1996. "Teaching Values." Pp. 531-47 in CQ Researcher 1996. Washington, DC: Congressional Quarterly.

Goodman, Paul. 1960. Growing Up Absurd: Problems of Youth in the Organized System. New York: Random House.

Healey, Melissa. 1996, May 28. "Concerned Parents Push Character Movement." Los Angeles Times, pp. A1 ff.

Hunter, James Davison. 1991. Culture Wars. New York: Basic Books.

--. 1994. Before the Shooting Begins: Searching for Democracy in America's Culture War. New York: Free Press.

Jackson, Philip W. 1968. Life in Schools. Troy, MO: Holt, Rinehart \& Winston.

Jackson, Philip W., Robert E. Boostrum, and David T. Hansen. 1993. The Moral Life of Schools. San Francisco: Jossey-Bass.

Kamens, David. 1992. "Variant Forms: Cases of Countries with Distinct Curricula." Pp. 74-83 in School Knowledge for the Masses, edited by John W. Meyer, David H. Kamens, and Aaron Benavot. London: Falmer Press.

Karabel, Jerome, and A. H. Halsey. 1977. "Introduction." Pp. 1-69 in Power and Ideology in Education, edited by Jerome Karabel and A. H. Halsey. New York: Oxford University Press.

Lareau, Annette. 1989. Home Advantage: Social Class and Parental Intervention in Elementary Education. London: Falmer Press.

Lortie, Dan. 1975. Schoolteacher. Chicago: University of Chicago Press.

McLaren, Peter L. 1989. Life in Schools. New York: Longman.

Meyer, John W. 1987. "Self and the Life Course: Institutionalization and Its Effects." Pp. 242-60 in Institutional Structure: Constituting State, 
Society and the Individual, edited by George M. Thomas, John W. Meyer, Francisco O. Ramirez, and John Boli. Newbury Park, CA: Sage.

Meyer, John W., David Tyack, Joanne Nagel, and Audri Gordon. 1979. "Public Education as Nation-Building in America, 1870-1930." American Journal of Sociology 85:591-613.

Neill, A. S. 1960. Summerhill: A Radical Approach to Child-Rearing. New York: Hart.

Parsons, Talcott. 1959. "The School Class as a Social Systems: Some of Its Functions in American Society." Harvard Educational Review 29:297-318.

Rosenfelt, Deborah S. 1994. "Definitive???: Women's Studies, Multicultural Education and Curriculum Transformation in Policy and Practice in the United States." Women's Studies Quarterly 22:26-41.

Rubinowitz, Leonard, and James E. Rosenbaum. 2000. Crossing the Class and Color Lines. Chicago: University of Chicago Press.

Sharp, Patricia, and Randy M. Wood. 1992. "Moral
Values: A Study of Selected Third and Fifth Grade Reading and Social Studies Textbooks." Religion and Public Education 19:143-53.

Tyack, David B. 1974. The One Best System. Cambridge, MA: Harvard University Press.

--. 1999. "Preserving the Republic by Educating Republicans." Pp. 63-84 in Diversity and Its Discontents: Cultural Conflict and Common Ground in Contemporary American Society, edited by Neil J. Smelser and Jeffrey C. Alexander. Princeton, NJ: Princeton University Press.

Tyack, David B., and Elizabeth Hansot. 1982. Managers of Virtue: Public School Leadership in America, 1820-1980. New York: Basic Books.

Waller, Willard. 1932. The Sociology of Teaching. New York: John Wiley \& Sons.

Willis, Paul. 1979. Learning to Labour: How WorkingClass Kids Get Working-Class Jobs. Westmead, England: Saxon House.

Wong, Sandra. 1991. "Evaluating the Context of Textbooks: Public Interest and Professional Authority." Sociology of Education 64:11-18.

Steven Brint, Ph.D., is Professor, Department of Sociology, University of California, Riverside. His main fields of interest are education, professions, political sociology, and theory. He is currently conducting a National Science Foundation-supported study of continuity and change in American colleges and universities, 1970-2000.

Mary F. Contreras, MA, is a graduate student, Department of Sociology, University of California, Riverside. Her main fields of interest are public policy, education, and gender. She is a consultant for a women's rights advocacy organization in Washington, DC.

Michael T. Matthews, MA, is a graduate student/researcher, Department of Sociology, University of California, Riverside. His main fields of interest are applied sociology, program evaluation, crime prevention, and urban sociology. He is conducting a federally funded evaluation of family preservation and family support programs in Riverside County, California.

The authors thank the California Educational Research Consortium for funding to support this study. They also thank Joyce Epstein, Richard Ingersoll, Corinne McKamey, Douglas Mitchell, John Modell, and Rodney Ogawa for comments that improved the quality of the article and Elizabeth Hansot and David Tyack for intellectual support at an early stage of the study. Address all correspondence to Dr. Steven Brint, Department of Sociology, University of California, Riverside, Watkins Hall 2144, Riverside, CA 92521; e-mail: steven.brint@ucr.edu. 